\title{
Applying the concept of resilience to pastoralist household data
}

\author{
John G. McPeak ${ }^{1 *}$ and Peter D. Little ${ }^{2}$
}

\begin{abstract}
This article explores the concept of resilience as outlined in a recent World Bank publication that applies the concept to rangeland areas in Africa. The paper does not attempt to speak to all of the dimensions of resilience and debates about the concept's applications to pastoral ecology and rangelands. Instead, we utilize a panel data set from northern Kenya and southern Ethiopia that has been analysed in other published studies to reconsider it from a resilience perspective. We show how different livelihood groups in the region are impacted by climate, disease, market, conflict, and land use shocks in a time characterized by a drought phase and a recovery phase. In many cases, there are livelihood-specific impacts of these shocks, and these help explain long-term herd dynamics and pastoralist poverty traps. Our analysis then turns to different ways of measuring resilience and finds that measurements of combined income and asset thresholds provide the most convincing outcomes. We further assess some broader opportunities and innovations that have the potential to enhance resilience in the drylands. Finally, different policy relevant steps that can be taken to enhance resilience are discussed in the context of the considerable heterogeneity in livelihood strategies which occurs in African rangelands.
\end{abstract}

Keywords: Resilience, Pastoralism, Livelihoods, Drylands, Shocks

\section{Introduction}

In this article, we will focus on the political economy of selected sub-Saharan dryland regions with specific attention to the social and political impacts of increasing market involvement. Our analysis and supporting arguments primarily draw on household data gathered in Kenya and Ethiopia quarterly from 2000 to 2002 supplemented by other data and experiences from the authors.

Our goal in the first half of this paper is to apply the 'Economics of Resilience in the Drylands of Sub-Saharan Africa' framework developed by the World Bank (2013) to a panel data set. We reviewed the themes of the World Bank framework and were curious to see how their implications might apply to the study area in East Africa for which there exists household level panel data. Of particular interest was how different sub-groups within pastoral economies might differ in terms of risk exposure, risk mitigation, and overall resilience to the multidimensional shocks defined in the World Bank document.

\footnotetext{
* Correspondence: jomcpeak@maxwell.syr.edu

'Syracuse University, Syracuse, NY, USA

Full list of author information is available at the end of the article
}

We decided to use the livelihood categories that had been identified in other analysis of this data set (McPeak et al. 2012) to draw out how different sub-groups in the population are differentially impacted by the shocks identified in the resilience framework. We use the heterogeneity in the data set to illustrate how different groups of people, here categorized by livelihood categories, are impacted by a variety of risks. Our analysis illustrates how livelihood groups differ in terms of exposure to shocks, sensitivity to shocks, and capacity to cope with shocks. Similar to earlier studies that found livelihood groups differ in terms of income generation, expenditure, and assets, this study investigates how these livelihood groups within dryland regions might also differ in how they experience shocks and the degree of their resilience (see Catley et al. 2012; McPeak et al. 2012). We will elaborate on how the concept of 'pastoral resilience in the drylands' is best conceived of as a heterogeneous concept where different sub-groups are experiencing shocks and resilience differently. This would indicate that policy responses to reduce risk exposure and enhance resilience will need to be targeted differently to help 
different sub-populations in dryland areas. In the conclusion, we will return to this theme.

\section{Study area}

To develop our analysis, we draw on data gathered as part of the Pastoral Risk Management (PARIMA) project, funded by the Global Livestock Collaborative Research Support Project (GL-CRSP)/USAID, supplemented by other research by the authors. As part of this project, surveys were conducted every three months of households in 11 communities of northern Kenya and southern Ethiopia from March 2000 to June 2002 (Figure 1). In the 11 sites represented, people identified themselves as II Chamus,
Turkana, Ariaal, Samburu, Pokot, Gabra, Rendille, Garre, Somali, Boran, and Burji (for brief historical and ethnographic accounts on these groups, see Schlee 1989; Spear and Waller 1993; Schlee and Watson 2009; chapter 2 in McPeak et al. 2012). This allows us to have a multi-ethnic group, multi-country sampling frame that straddles production systems ranging from settled agro-pastoral to nomadic pastoral.

In each of the 11 sites, 30 households were randomly selected from area-specific population lists and were interviewed in a baseline round in March 2000 and these same households were interviewed at the end of every three-month period over the next two years until June

\section{Survey Sites in Southern Ethiopia and Northern Kenya}

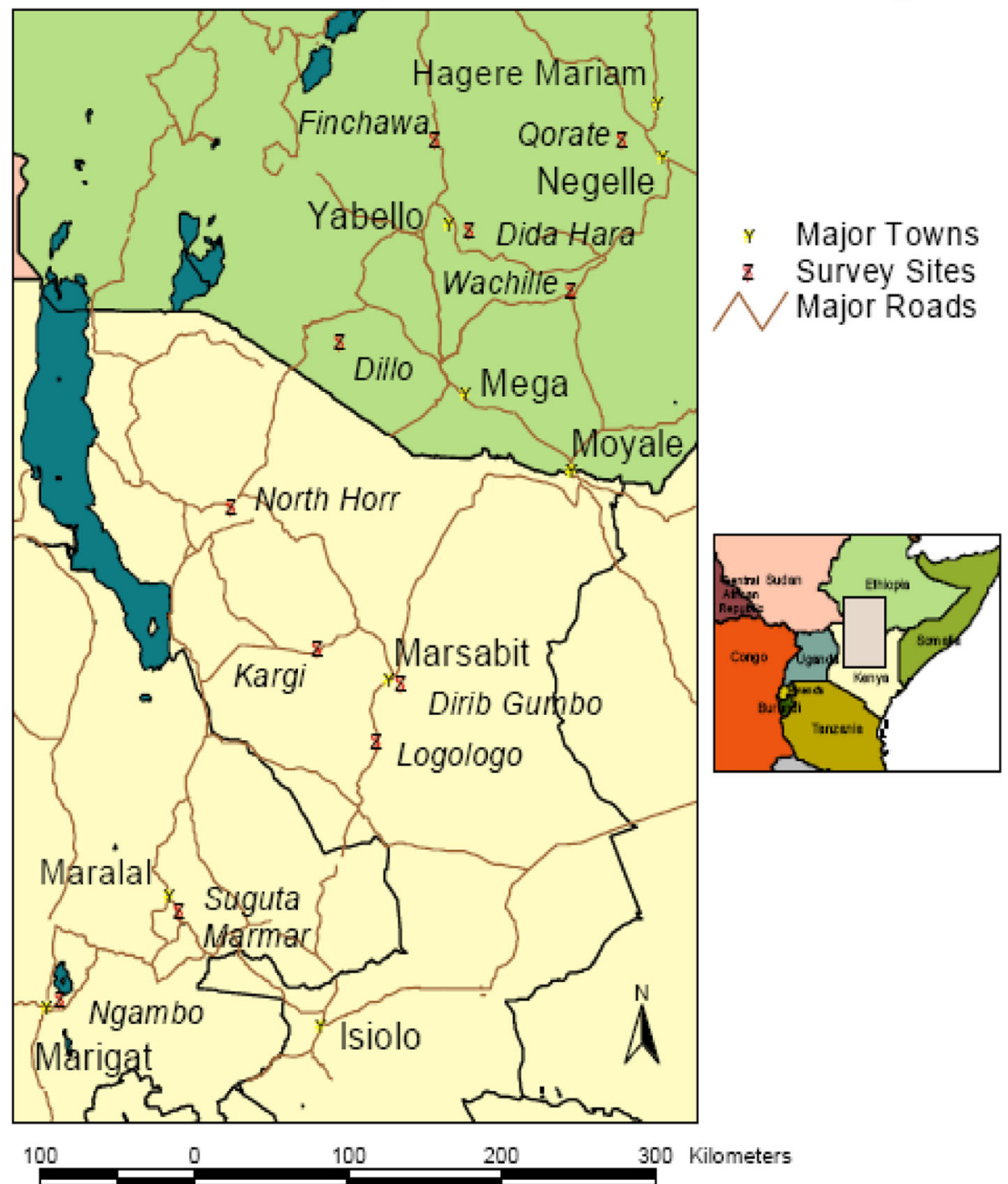

Figure 1 Map of study sites 
2002. The three-month blocks correspond to a rainy season or a dry season in this bi-modal rainfall system. As events transpired, the baseline in March 2000 was conducted just as a significant regional drought was commencing. This drought impacted households over the second half of 2000 and into 2001 before more normal rainfall conditions returned in the second half of 2001 and first half of 2002 (see McPeak et al. 2012, p. 56-59, for rainfall and NDVI patterns during these periods in the study sites). In our analysis, the period March 2000 to June 2001 is treated as a 'drought phase' and the following periods to June 2002 as a 'recovery phase'.

We decided to return to this data set for two main reasons. First, the unusually detailed information contained in the data set, the large geographic spread of the sites, and the timing of the study covering a drought and recovery period make it possible to conduct detailed analysis that is applicable to a large multi-ethnic sample of households in African drylands under conditions of drought and recovery. For the purposes of assessing pastoral resilience in the face of climate shocks, the data set is particularly suited to the task and also as far as we know the only data set of this kind currently available. Second, some in-depth analysis of the data from a livelihood perspective has already been conducted (McPeak et al. 2012), making it possible to contrast insights from a livelihood perspective with insights from a resilience perspective. For these reasons, we decided to analyse this data set to test the utility of the World Bank resilience framework. In so doing, we fully recognize that a significant amount of time has passed since the data were gathered and that major changes have occurred in the area such as transport infrastructure improvement, the rapid spread of cell phone networks, and larger changes in the political economy of both Kenya and Ethiopia. We turn to some of these developments near the closing of the paper when considering resilienceenhancing opportunities in the study area. However, we anticipate that much of the main argument positing that risk exposure and resilience are experienced differently by different kinds of households within dryland areas, and that this matters for resilience programming in dryland areas, remains valid if perhaps in need of updating and refining should more current multi-site household data sets become available.

\section{Methods}

\section{Resilience framework}

The World Bank's 'Concept Paper on the Economics of Resilience in the Drylands of Sub-Saharan Africa' (January 2013) identifies four key shocks to dryland production systems: climate, health, market, and conflict. Across these four shocks, households may differ in exposure to the risk, sensitivity to the shock, and capacity to cope with the shock. We apply this framework to investigate different types of shocks and determinants of vulnerability using the data from northern Kenya and southern Ethiopia.

Our objective is twofold. First, we seek to apply the framework to a rich and detailed data set gathered from households in a dryland area. The relative intensity and timing of this survey captures detailed household-level data that is of interest for considering resilience to shocks in a set of communities that experienced periods of climate shock and recovery. Second, important policy messages are revealed when seeing how these shocks and vulnerabilities are experienced at the household level and by sub-groups in different livelihood categories.

\section{Livelihood analysis}

To place some structure on the heterogeneity within the population of dryland areas, we draw on previous work analyzing this data set from a livelihood perspective presented in McPeak et al. 2012. The livelihood groups are differentiated by access to two key resources: the cash economy and livestock assets. ${ }^{1}$ Our measure of household cash income (per person per day and converted into US dollars at the prevailing exchange rate) captures access to the cash economy. We stratify households based on the cash value of this variable in the June 2000 survey round which covered the previous three months (a rainy season).

For livestock wealth, a measure of herd size is converted into tropical livestock units (TLUs) and expressed in per capita values. A TLU represents $250 \mathrm{~kg}$ live weight of an animal, and in our calculation, 0.7 camel $=1$ head of cattle $=10$ sheep or goats $=1$ TLU (Schwartz et al. 1991). We use the values for this variable from the baseline survey conducted in March 2000, which is the start of the period over which the cash income variable also is defined.

\section{Analysis \\ Livelihood analysis}

Households were assigned to one of four groups depending on their herd size per capita in the baseline survey in March 2000 and cash income per capita in the repeat survey in June 2000. Households were ordered by each of these two variables and assigned to groups above or below the median of these respective variables. Table 1 presents the names we applied to the groups and the percentage of the population in each.

Table 1 Livelihood groups in the study region sample

\begin{tabular}{lll}
\hline & Lower cash income & Higher cash income \\
\hline Lower herd size & Left out 29\% & Moving from 21\% \\
Higher herd size & Staying with 21\% & Combining 29\% \\
\hline
\end{tabular}


The rationale for these groupings is that they correspond to four broadly drawn sub-categories of the population in this area. One is the lower cash, lower herd-ownership group - the 'left out' group - since they have lower access to both herds and the cash economy than the other groups and are the most impoverished group. A second group is the higher cash, lower herd-ownership group, called the 'moving from' group. They reside in dryland areas but are moving in a direction away from a herd-based livelihood to occupy other niches in the local economy. A third group is the lower cash, higher herd group, labeled as 'staying with' pastoralism but not engaging with the cash economy to the degree seen in their peers. Finally, the higher cash, higher herd group, the 'combining' group, is strongly involved in both pastoralism and the cash economy relative to others.

After stratifying this sample, we calculated a value for household total income in which all home-produced and home-consumed goods are assigned community-specific market values and this is added to the measure of cash income reported in the interviews. ${ }^{2}$ The distinction between total income and cash income is an important one as a large share of total income comes in the form of home-produced and home-consumed milk in this area. The differing experiences of these distinct groups during the study period are illustrated using two measures: (i) mean household total income for the households stratified by livelihood category in subsequent repeat rounds of the survey, an income-based measure of well-being, and (ii) the coefficient of variation (cv) about this mean income as revealed by further survey rounds, a vulnerability measure of well-being. While all the income values in Table 2 are categorized as 'poor' by any conventional threshold, it is still evident that the left out group is relatively worse off in terms of mean income and the combining group is relatively better off by this measure. The other two livelihood categories lie in between these two cases. In Table 2, we also present the average herd size in subsequent rounds, showing that the stratification based on the initial round is reflected in outcomes over subsequent survey rounds.
Figure 2 shows total income disaggregated by sources of income for each livelihood group. Milk that is homeproduced and almost entirely home-consumed ranges from 38 to $58 \%$ of total income for the sub-groups. It is important to stress that in this economy, milk production is a major production objective and these households are critically reliant on milk. The milk production orientation of pastoralist herds in drylands is further demonstrated in their herd structures. Using more recent data from the Borana zone of southern Ethiopia, which has experienced a rapid growth in livestock trade since 2002, local herds of cattle still are $79 \%$ female, goats $79 \%$ female, and camels $74 \%$ female in 2013 . These data reflect production strategies strongly oriented towards milk production and herd growth rather than live animal trade, which strongly favours young bulls that are in the highest market demand (Little 2013a; Debsu 2013). Livestock marketing is critically important in the study region, but unlike parts of West Africa - a region with a longer history of livestock trade than the Horn of Africa - only a small fraction of household herds $(<7$ to $8 \%$ in most cases) are composed of the types of male animals that are generally sought in livestock markets. By contrast, there has been a noticeable increase in the percentage of young male animals in pastoralist herds of West Africa in response to market demand, with some pastoralist communities specializing in the supply of immature males to agro-pastoralists who then fatten the animals to meet urban demand (Amanor 1995; Wane et al. 2010a).

The household-level decision to allocate milk to markets, home consumption, or suckling animals has been a topic of prior research. Wealth plays an important role in determining milk offtake from the herd, with wealthier households leaving more milk for the animal to consume, resulting in better calf health (Holden et al. 1991; Sikana and Kerven 1991). De'Besi and Thieme (2013) argue that in many tropical systems, including those in pastoral areas of Africa, it is appropriate to have higher rates of milk offtake at the expense of herd growth. Recent demand in livestock markets may be creating an incentive to focus more on herd growth and the

Table 2 Average herd size and income measures by sub-group

\begin{tabular}{|c|c|c|c|c|}
\hline Group & Herd size TLU & $\begin{array}{l}\text { Total income per } \\
\text { capita per day }\end{array}$ & $\begin{array}{l}\text { Cash income as \% of } \\
\text { total income }\end{array}$ & Total income variability (cv) \\
\hline 1) Left out & 7.3 & $\$ 0.20$ & $29 \%$ & 1.32 \\
\hline 2) Moving from & 7.2 & $\$ 0.27$ & $46 \%$ & 0.90 \\
\hline 3) Staying with & 23.7 & $\$ 0.34$ & $21 \%$ & 0.82 \\
\hline 4) Combining & 26.0 & $\$ 0.46$ & $35 \%$ & 0.63 \\
\hline $\begin{array}{l}\text { Significant difference in } \\
\text { means by groups, } t \text {-statistics }\end{array}$ & $\begin{array}{l}t 12, t 13^{* * *}, t 14^{* * *}, \\
t 23^{* * *}, t 24^{* * *}, t 34^{\prime}\end{array}$ & $\begin{array}{l}t 12, t 13, t 14^{* *} \\
t 23, t 24^{* * *}, t 34\end{array}$ & $\begin{array}{l}t 12^{* * *}, t 13^{* *}, t 14^{*} \\
t 23^{* * *}, t 24^{* * *}, t 34^{* * *}\end{array}$ & $\begin{array}{l}t 12^{* *}, t 13^{* * *}, t 14^{* * *}, \\
t 23, t 24^{* * *}, t 34^{* * *}\end{array}$ \\
\hline
\end{tabular}

***Significant difference at $1 \%,{ }^{* *}$ significant difference at $5 \%,{ }^{*}$ significant difference at $10 \%$ 


\section{Total income sources}

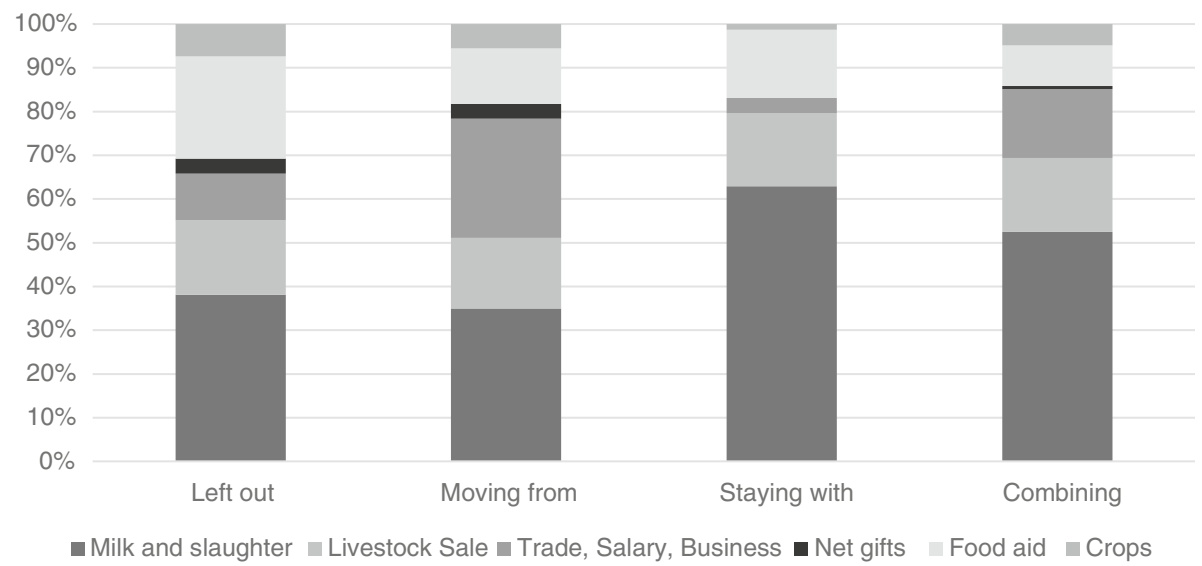

Figure 2 Total income sources by livelihood group

production of male animals for eventual marketing as is more common in West Africa. It is a researchable topic worth monitoring; to what extent will improvements in livestock markets influence household-level decisions to increase milk offtake? Does the increased value of meat production draw resources away from milk offtake? When we factor in that control over milk and milk marketing and livestock marketing have gendered and that there are household-level nutritional implications (Herren 1992; Sikana et al. 1993; Nduma et al. 2001; Fratkin and Roth 2004; McPeak and Doss 2006), the case for further research on this topic is even more compelling.

\section{Heterogeneity and inequality}

While the definition of the groups worked on the basis of the median of the distribution of herd size and cash income, it is important to consider the unequal distribution of access to these two resources and total income. Figure 3 illustrates that access to cash income, total income, and livestock wealth are very unequal in the sample, as is generally true for African pastoralist communities (see Little et al. 2001). The Lorenz curves used in Figure 3 show the cumulative percentage of the population that controls a cumulative percentage of the given variable. The cumulative percent of the income or asset is recorded on the $y$-axis, and the cumulative percent of the

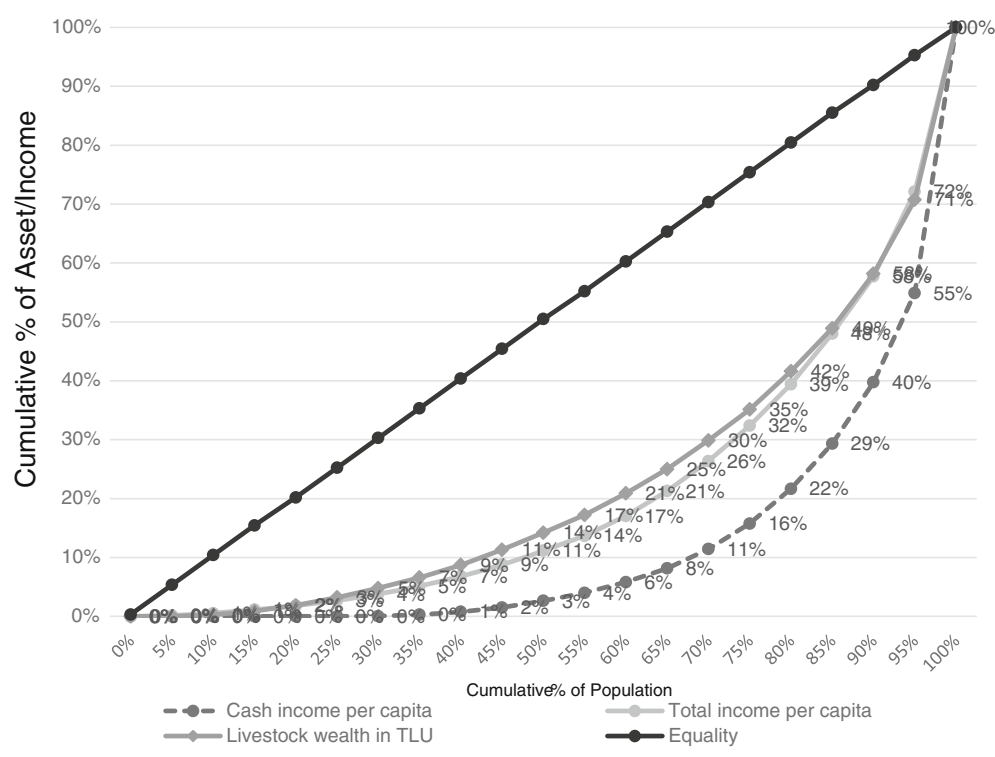

Figure 3 Lorenz curves for total income, cash income, and livestock wealth 
population is recorded on the $x$-axis. If there is perfect equality in the distribution of the variable, the percent of the population and the percent of the value are identical and the Lorenz curve is a $45^{\circ}$ line. In contrast, for example, the figure illustrates that the poorest $30 \%$ of the sample controls only $4 \%$ of the total income of all households. Additionally, it shows the upper 10\% of households control $42 \%$ of total livestock wealth. There is pronounced inequality in the surveyed population. We will discuss below how these inequalities lead to differing degrees of vulnerability to shocks.

\section{Shock exposure, sensitivity, and coping capacity Climate shocks}

Both rainfall records and normalized difference vegetation index (NDVI) imagery reveal the period 2000 to 2001 was a covariate drought shock that covered the entire study area (McPeak et al. 2012); 2001 to 2002 was the initial phase of a longer recovery, though the timing of the transition from drought to recovery in 2001 revealed some spatial variation. In our analysis, we treat June 2001 as the end of the drought phase. In terms of exposure to climate shock, all households were exposed to the covariate drought shock, though some directly through the impact on livestock production and others more indirectly through the secondary effects of livestock producers having less money to spend in the local economy.

How sensitive were households to climate shock? Given the importance of home-produced and homeconsumed milk to total income illustrated in Figure 3, one domain to explore the importance of milk is in terms of food security from household production. Households are exposed to the risk that climate shocks will negatively impact this critically important component of household consumption. Table 3 illustrates that the livelihood categories with larger herds are more sensitive to this shock in one sense, as they confront larger variation over time in household milk production. However, in relative terms as captured by the coefficient of variation, the staying with and combining groups are significantly less sensitive to fluctuations in milk than the left out group, while the moving from group is not statistically different from the groups with the larger herds.

Another domain to consider is the impact of drought on herd growth. Livestock are critical to income generation in both milk production and livestock sales, so that both current and future food security are directly linked to herd size dynamics. Concerning herd loss attributed to drought, with the possible exception of the moving from category having a lower rate of drought mortality than the staying with group, Table 4 illustrates that a roughly similar percent of all mortality recorded for the sub-groups is due to the commonly experienced climate shock. Though individual realizations differ, from a statistical point of view across these groups, this is generally a covariate shock.

To further investigate herd dynamics and ways in which they may potentially differ by livelihood group, Table 4 presents the seasonal (three month) average animal birth and death rates ${ }^{3}$ by livelihood category and by drought (June 2000 to June 2001) and recovery periods (September 2001 to June 2002).

First, note that for all groups, the herd size changes in drought and recovery periods are driven more by variation in death rates than birth rates. Birth rates are lower in the drought period than the recovery period, but the magnitude of this difference is much less than a similar comparison across periods for death rates. Second, the moving from group appears less variable across drought and recovery phases than the other groups, perhaps due to their more sedentary production system and use of cash to purchase livestock production inputs. In contrast, the left out group that is also more sedentary is the hardest hit by the drought death rate. One interpretation is that those who were more sedentary but had access to cash are able to purchase inputs to support livestock through droughts.

What was the capacity of households to deal with the climate shock? We explore four main mechanisms, three that seemed to work and one that did not. First, herders can respond to drought by increasing livestock sales to buffer the loss of milk. However, they do so at the cost of further reducing the drought-depleted herd and future

Table 3 Average household daily milk production, variation over periods in the average, and corresponding coefficient of variation in milk production by household group

\begin{tabular}{lll}
\hline & $\begin{array}{l}\text { Mean milk L per } \\
H H \text { per day }\end{array}$ & $\begin{array}{l}\text { Average variation per HH } \\
\text { coefficient of variation }\end{array}$ \\
\hline Left out & 1.2 & 4.4 \\
Moving from & 1.6 & 6.2 \\
Staying with & 3.1 & 17.4 \\
Combining & 3.3 & 13.6 \\
Significant difference in means & $t 12^{*}, t 13^{* * *}, t 14^{* * *}$, & $t 12, t 13^{* * *}, t 14^{* *}$, \\
by groups, $t$-statistics & $t 23^{* *}, t 24^{* * *}, t 34$ & $t 23^{* *}, t 24^{*}, t 34$
\end{tabular}

***Significant difference at $1 \%,{ }^{* *}$ significant difference at $5 \%,{ }^{*}$ significant difference at $10 \%$ 
Table 4 Mortality due to climate shock and 3-month birth, death rates drought and recovery

\begin{tabular}{llllll}
\hline & $\begin{array}{l}\text { Share of all mortality } \\
\text { due to climate shock }\end{array}$ & Drought birth rate & Recovery birth rate & Drought death rate & Recovery death rate \\
\hline 1) Left out & $56 \%$ & $7.8 \%$ & $10.3 \%$ & $13.0 \%$ & $0.7 \%$ \\
2) Moving from & $46 \%$ & $6.2 \%$ & $9.2 \%$ & $6.6 \%$ & $2.5 \%$ \\
3) Staying with & $57 \%$ & $10.7 \%$ & $11.7 \%$ & $11.1 \%$ & $1.5 \%$ \\
4) Combining & $53 \%$ & $6.4 \%$ & $10.6 \%$ & $9.5 \%$ & $0.9 \%$ \\
Significant difference in & $t 12, t 13, t 14$, & $t 12, t 13^{* *}, t 14^{* * *}$, & $t 12, t 13, t 14$, & $t 12^{* * *}, t 13, t 14^{*}$, & $t 12, t 13^{*}, t 14$, \\
means by groups, $t$-statistics & $t 23^{*}, t 24, t 34$ & $t 23, t 24, t 34^{* * *}$ & $t 23^{* *}, t 24, t 34$ & $t 23^{* *}, t 24^{*}, t 34$ & $t 23, t 24, t 34$ \\
\hline
\end{tabular}

***Significant difference at $1 \%,{ }^{*}$ significant difference at $5 \%,{ }^{*}$ significant difference at $10 \%$

recovery (Table 5). Further, they could potentially selfrestock in the recovery period by purchasing livestock.

The moving from group stands out from the others in that they are much more market oriented in adjusting their herd size; they sold at a much higher rate in the drought as well as the recovery and they purchase more in both the drought and recovery. The staying with and left out groups are the least flexible with adapting sales and purchase rates to changing conditions as sales rates are essentially invariant to the period; the other two groups show the anticipated pattern of sales rates being higher in the drought than in the recovery phase.

A second way to deal with the climate shock is the classic pastoral strategy of mobility. If pastures are insufficient due to poor or no rainfall, herds can be moved to areas where sufficient grazing can be found. In the study area, most households undertake mobility by sending animals to a remote satellite camp, thereby splitting household herds and household members to allow livestock mobility. Table 6 characterizes this mobility by the average number of water point households used for remote (satellite) grazing points per season in the drought and recovery phases.

There is clear variation both across livelihood groups and within them over time. The groups with larger herds practised more mobility as captured by this measure. All groups practised more average mobility in the drought phase than in the recovery phase. The combining group is by far the most mobile as captured by this measure, with the staying with group next, although the latter group's mobility is not statistically different than the moving from group. There is some difference in the moving from and left out groups, though it seems clear that overall, the left out group is less mobile than the other groups. As presented elsewhere (Little et al. 2008; McPeak et al. 2012), those households with a high degree of mobility experienced less herd mortality during drought than others. Taken together with the milk and herd sales findings, these findings illustrate that there may be links between mobility patterns, herd growth, and future food security.

To look at the bigger picture influencing herd dynamics, the net impact of the herd size changes discussed in this section on herd dynamics over time are captured in Figure 4. This illustrates the size of the average household herd in comparison to where they were in the first baseline survey of March 2000 as they moved through drought and onset of recovery.

In Figure 4, the left out group is clearly the most sensitive to the overall impact of the drought event. They endured the largest proportional loss and never fully recovered over the two-year period. When the study ended, they were still over $20 \%$ behind where they started on average. The staying with group also had not recovered fully but had come closer to where they started after suffering a smaller shock. The combining and moving from groups had recovered to a point that they had larger herds than they began with, on average. These longer term herd dynamics, and the forces that underlie them as elaborated on in this section, illustrate

Table 5 Three month sales and purchase rates in drought and recovery

\begin{tabular}{lllll}
\hline & Sales rate drought & Sales rate recovery & Purchase rate drought & Purchase rate recovery \\
\hline 1) Left out & $3.2 \%$ & $3.3 \%$ & $0.6 \%$ & $0.7 \%$ \\
2) Moving from & $6.7 \%$ & $5.0 \%$ & $2.2 \%$ & $2.2 \%$ \\
3) Staying with & $2.0 \%$ & $2.1 \%$ & $0.5 \%$ & $0.3 \%$ \\
4) Combining & $3.4 \%$ & $2.9 \%$ & $0.5 \%$ & $0.5 \%$ \\
Significant difference in & $t 12^{* * *}, t 13^{* * *}, t 14$, & $t 12^{* * *}, t 13^{* * *}, t 14$, & $t 12^{* * *}, t 13^{*}, t 14$, & $t 12^{* * *}, t 13^{*}, t 14$, \\
means by groups, $t$-statistics & $t 23^{* * *}, t 24^{* * *}, t 34$ & $t 23^{* * *}, t 24^{* * *}, t 34^{* *}$ & $t 23^{* * *}, t 24^{* * *}, t 34$ & $t 23^{* * * *}, t 24^{* * *}, t 34$ \\
\hline
\end{tabular}

***Significant difference at $1 \%,{ }^{*}$ significant difference at $5 \%,{ }^{*}$ significant difference at $10 \%$ 
Table 6 Number of remote (satellite) camp water points used per season during the drought and recovery by group

\begin{tabular}{lll}
\hline & $\begin{array}{l}\text { Average \# remote } \\
\text { camps used per season } \\
\text { in drought }\end{array}$ & $\begin{array}{l}\text { Average \# remote } \\
\text { camps used per season } \\
\text { in recovery }\end{array}$ \\
\hline 1) Left out & 0.24 & 0.18 \\
2) Moving from & 0.40 & 0.28 \\
3) Staying with & 0.53 & 0.46 \\
4) Combining & 0.92 & 0.70 \\
& $t 12^{*}, t 13^{* * *}, t 14^{* * *}$, & $t 12^{*}, t 13^{* * *}, t 14^{* * *}$, \\
& $t 23, t 24^{* * *}, t 34^{* * *}$ & $t 23, t 24^{* * *}, t 34^{*}$
\end{tabular}

***Significant difference at $1 \%,{ }^{* *}$ significant difference at $5 \%,{ }^{*}$ significant difference at $10 \%$

critical aspects of resilience: asset vulnerability, asset recovery, and the critical mapping of asset levels into income and food security.

As a final perspective on coping with food security shocks, we consider the role of exogenous support such as food aid in confronting exposure to, sensitivity to, and ability to cope with a food security shock. For the left behind group, proportionately, food aid plays a large role; it accounts for around 23\% of total income coming into these households on average (see Figure 2). To compare the size of food aid inflows into the different categories of households, Table 7 illustrates that in terms of the value of food aid ${ }^{4}$ per capita per day coming into the different categories of households.

Table 7 illustrates that food aid appears to be moderately well targeted at the more vulnerable households and away from the less vulnerable households, as the left behind group gets the largest amount and the combining group gets the smallest amount. However, Figure 5 places this finding in a broader context by presenting overall total income per capita per day for households in the Kenya sample in contrast to the Ethiopia sample and, for each country, the income inclusive and exclusive of the value of food aid. We present it by country as food aid is often implemented as a response to an appeal by national government. This illustrates two main points. First, contrary to the idea sometimes expressed that dryland populations are food aid-dependent and surviving on food aid, Figure 5 illustrates that external food assistance is a discernible but relatively minor component of overall income. We want to stress that the value of what pastoral people produce overwhelmingly exceeds what they get from external actors. Second, while food aid appears to have some success in targeting more vulnerable groups, temporally, food aid is not well targeted to smooth out consumption drops, as it does not 'fill in gaps' of production declines during droughts, but seems to flow for reasons unrelated to the larger pattern of household total income over time. Food aid does not appear to have a major impact on enhancing household capacity to cope with climate shocks though does seem to be moderately well targeted to more vulnerable groups when it is available.

\section{Human and animal health shocks}

Exposure to health shocks can be divided into human health shocks and animal health shocks in this pastoral setting. To get a sense of what kinds of health problems confront people in the study area, we can turn to their descriptions of what kinds of health shocks they experienced. The following human illness and injuries were reported by all households (McPeak et al. 2012): 50\% malaria; $10 \%$ injuries and accidents; another $10 \%$ respiratory problems; $7 \%$ coughs, colds, or ear infections; $6 \%$ diarrhoea; $4 \%$ fevers; $3 \%$ headaches; $2 \%$ eye problems; another $2 \%$ which were gynaecological; and 17 other distinct types of problems account for the remaining $6 \%$ of cases reported with each accounting for less than $1 \%$.

To record outbreaks of animal diseases, McPeak et al. (2012) used the community reported monthly observations to get a sense of what kinds of diseases were prevalent in each community over time. They report the following. 'Animal disease outbreaks were reported in $12 \%$ of the community monthly observations. Thirty-six percent of the outbreaks were of a type of Pneumonia.

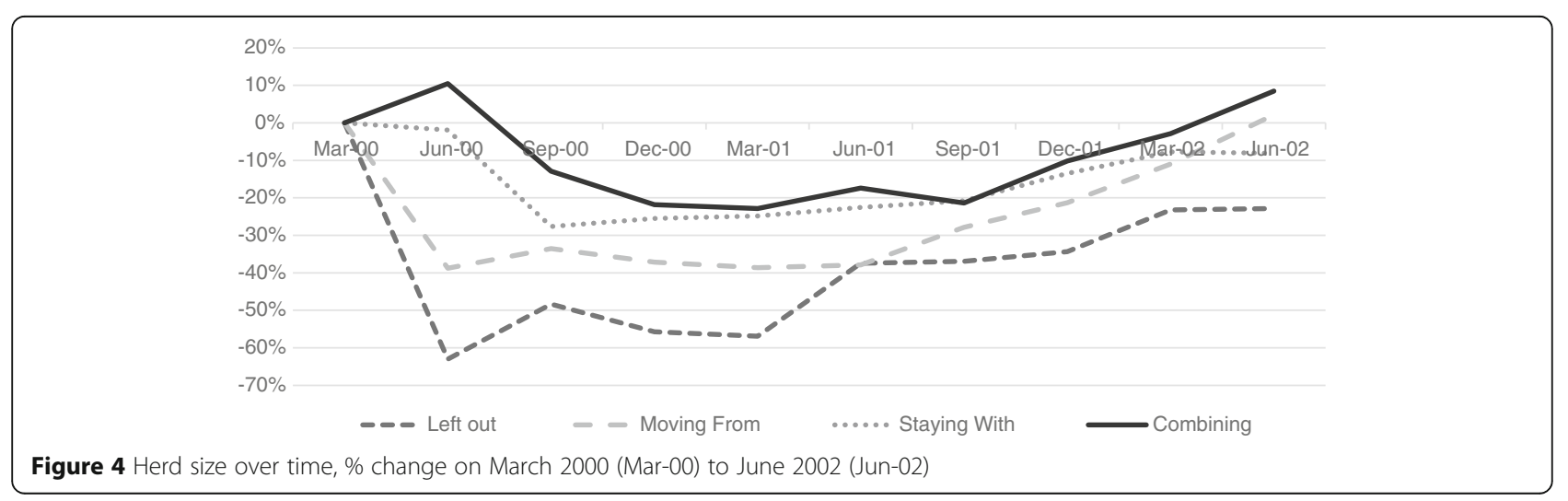


Table 7 The cash value of food aid per capita per day by $\mathrm{HH}$ group

\begin{tabular}{ll}
\hline & Cash value of food aid per capita \\
\hline 1) Left behind & $\$ 0.231$ \\
2) Moving from & $\$ 0.127$ \\
3) Staying with & $\$ 0.156$ \\
4) Combining & $\$ 0.093$ \\
& $t 12^{* * *}, t 13^{* *}, t 14^{* * *}, t 23, t 24^{* *}, t 34^{* * *}$ \\
\hline
\end{tabular}

***Significant difference at $1 \%,{ }^{* *}$ significant difference at $5 \%$, ${ }^{*}$ significant difference at $10 \%$

The next most common was foot and mouth disease (18\%). Lymphoniditis and cowpox each accounted for $10 \%$ of reported outbreaks, skin disease $8 \%$, and Trypsonomaisis 5\%' (p. 70).

Sensitivity to health shocks is investigated across survey rounds and across the livelihood categories in Table 8 . Table 8 reports the share of survey rounds in the drought period and in the recovery period for which any adverse health event was reported at the household level. First, note that all groups experienced a higher illness incidence during the drought. The climate risk has an adverse impact on human health as suggested by the World Bank framework introduced above. Comparing across groups during the drought phase, the staying with group suffered notably lower rates of illness, which may reflect their lower attachment to town-based market activities. This potentially echos the findings of Fratkin et al. (2004) that human health is negatively correlated with degree of sedentarization. The staying with group stands out for the relative stability and low level of their sensitivity to human illness. Also notable is that in the recovery phase, there are no significant differences across groups in the incidence of health events. The differentiation in human health shocks across groups becomes evident when the pastoral system is under stress in a drought, but is not differentiated when the system is in a recovery phase.
For animal illness sensitivity, we again draw on households' explanations for livestock mortality. As reported in the final column of Table 8, of all animal deaths reported, animal disease was cited as the cause for $31 \%$ of deaths for the left out group, $40 \%$ of deaths for the moving from group, $21 \%$ of deaths for the staying with group, and $27 \%$ of deaths for the combining group. The staying with group is less exposed to disease transmission relative to the more sedentary groups. We can also pair the relatively low drought loss for the moving from group reported in Table 4 with the relatively high animal disease exposure reported in Table 8 for this group to interpret their smaller herds and lower mobility exposing them differently to animal loss than may be the case for the other groups.

Capacity to cope with health shocks In addition to mobility as a possible avoidance strategy of human and animal diseases that occur where population density might be higher (see Table 6), capacity to cope with human and animal health shocks could be reflected in household expenditures on health care and animal inputs. Table 9 reports these findings over all survey periods for the different household groups. As suggested above, the moving from group spends more in veterinary inputs than the left out and staying with group. The larger pattern is that the higher cash groups of moving from and combining spend more than the lower cash groups on both human health and livestock inputs, though to varying degrees of significance. This does highlight that the benefits of health and livestock services are in some cases conditional on access to cash income.

\section{Market shocks}

In addressing exposure to market shocks, it is important to consider that prices for the essential traded commodities change quite substantially due to droughts. The revenue people obtain from selling animals is

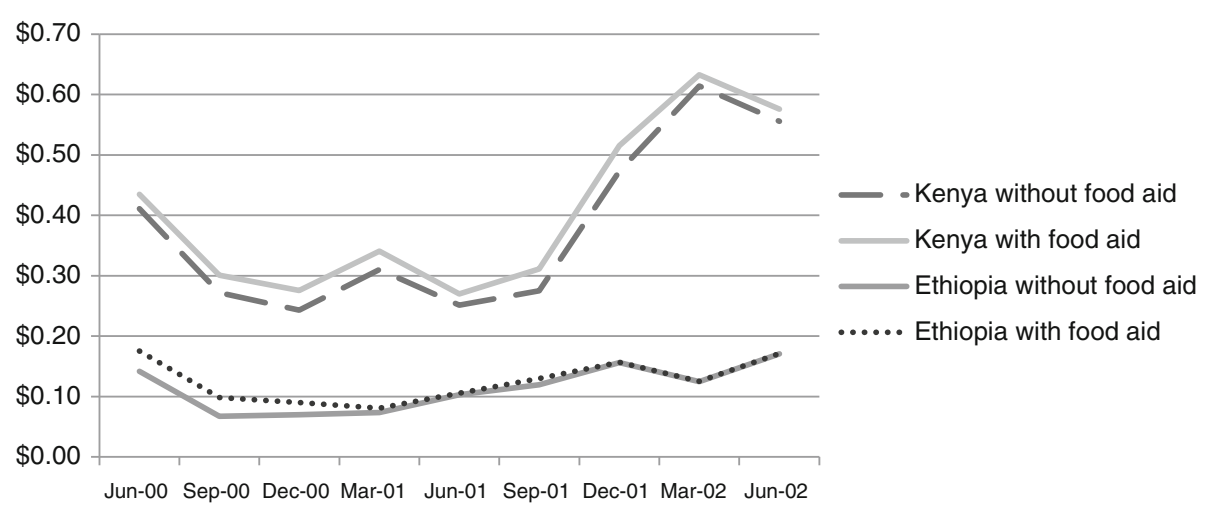

Figure 5 Total income inclusive and exclusive of food aid over time in Kenya and Ethiopia 
Table 8 Human and animal disease incidence

\begin{tabular}{llll}
\hline & $\begin{array}{l}\text { Seasons with human } \\
\text { health events in drought }\end{array}$ & $\begin{array}{l}\text { Seasons with human } \\
\text { health events in recovery }\end{array}$ & $\begin{array}{l}\text { Share of all livestock mortality } \\
\text { due to disease shock }\end{array}$ \\
\hline 1) Left behind & $27.0 \%$ & $11.0 \%$ & $31 \%$ \\
2) Combining & $38.3 \%$ & $15.8 \%$ & $40 \%$ \\
3) Staying with & $15.6 \%$ & $11.5 \%$ & $21 \%$ \\
4) Combining & $23.8 \%$ & $13.0 \%$ & $27 \%$ \\
& $t 12^{* *}, t 13^{* * *}, t 14, t 23^{* * *}, t 24^{* * *}, t 34^{* *}$ & $t 12, t 13, t 14, t 23, t 24, t 34$ & $t 12, t 13^{*}, t 14, t 23^{* * *}, t 24^{* *}, t 34$ \\
\hline
\end{tabular}

***Significant difference at $1 \%,{ }^{* *}$ significant difference at $5 \%,{ }^{*}$ significant difference at $10 \%$

temporally variable (see Barrett et al. 2003; Barrett and Luseno 2004). Many households adopt a livestock sales strategy - distress sales - to cope with food insecurity. Recent research shows that a major reason why pastoralists of the Senegalese Sahel use livestock markets is to satisfy consumption needs, which are aggravated during dry seasons and droughts (Wane et al. 2010a). Consequently, markets become saturated with poor condition animals, which sell for much lower prices. Simultaneously, an increase in demand by livestock owners for purchased grains can lead to price increases as more demand chases a limited supply if markets function as theory predicts. Livestock producers are caught from both sides when production and food security conditions are bad (for earlier work on this issue, see Swift 1979) and are further exposed to the risk that livestock markets may be characterized by market power by traders. Figure 6 illustrates this point. The solid bold line records the average price per TLU in USD (divided by $\$ 100$ for scaling reasons); the other three lines are prices for maize, sugar, and milk. Livestock prices are lowest when commodity prices are highest and highest when commodity prices are lowest. Milk is a possible exception. If herders have any milk to sell in a drought, milk prices are higher.

How might these price differences impact the livelihood categories differently? We assume the market prices for purchased goods are the same across the different kinds of households (though admit this could merit investigation with a different data set). We do have household-level evidence on the prices received for

Table 9 Health and veterinary input expenditure per season

\begin{tabular}{lll}
\hline & $\begin{array}{l}\text { Health } \\
\text { expenditure }\end{array}$ & $\begin{array}{l}\text { Vet input } \\
\text { expenditure }\end{array}$ \\
\hline 1) Left out & $\$ .0004$ & $\$ 0.004$ \\
2) Moving from & $\$ 0.014$ & $\$ 0.019$ \\
3) Staying with & $\$ 0.008$ & $\$ 0.003$ \\
4) Combining & $\$ 0.007$ & $\$ 0.010$ \\
Significant difference in & $t 12^{* *}, t 13, t 14^{*}$, & $t 12^{* *}, t 13, t 14$, \\
means by groups, $t$-statistics & $t 23, t 24, t 34$ & $t 23^{* *}, t 24, t 34$ \\
\hline
\end{tabular}

***Significant difference at $1 \%,{ }^{* *}$ significant difference at $5 \%,{ }^{*}$ significant difference at $10 \%$ animals sold by households over time. We calculate the price per TLU received by each household in each survey round and express these in terms of the drought period and recovery period in order to investigate whether prices received for livestock vary over time and across livelihood categories. We report our findings in Table 10.

To begin with, note that there are no statistically significant differences across groups in the drought phase. Further, for all but the left out group, the average price per TLU increases in the recovery phase compared to the drought phase. In addition, the differences across groups in the recovery phase become significant in a variety of comparisons but most noticeably in the left out group receiving less per TLU than all the other groups. There is some further evidence that the moving from and combining groups do better than the staying with group as well. The main finding to stress with regard to the left out group is they are left out in a further dimension; prices of livestock for the other groups recover as the drought ends, but they remain relatively stagnant for the left out group. If we recall from Table 5 that they sell about the same rate in both drought and recovery, we see that they may fall further behind the other groups in recovery. Note that the decline in sales rates seen in the recovery phase for the moving out and combining groups may be possible due to the higher price per TLU they are realizing. Perhaps, the left out groups are less able to bargain as immediate consumption needs take priority as suggested by the results of Turner and Williams (2002), or possibly, the animals are in qualitatively worse condition due to the limited mobility and limited access to inputs revealed in the data analysis presented above.

Capacity to cope with market shocks The capacity to cope with market shocks in many ways reflects the capacity to cope with climate shock, as covariate market and climate risk are highly interconnected. We can further expand by considering the previous findings on health shocks. If a household has a bigger herd, it has more milk. If the household can migrate to better pastures, it can further increase milk production. This can 


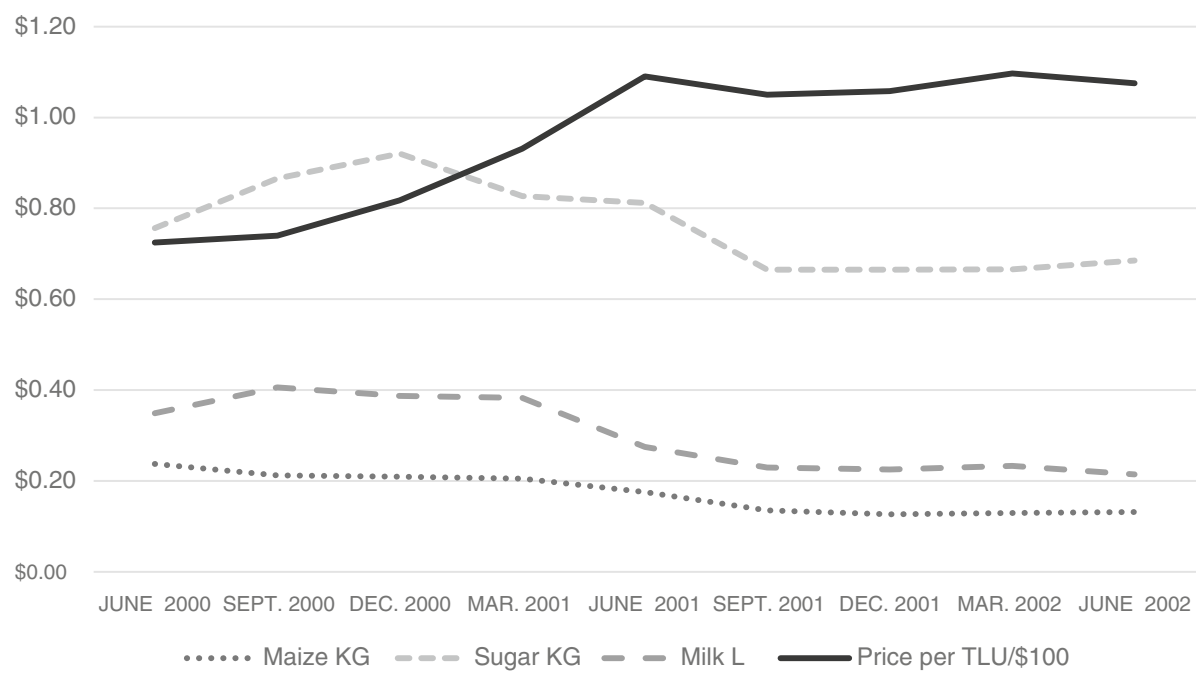

Figure 6 Average prices over time for commodities purchased and livestock sold

make a household less vulnerable to market shocks, as the milk production provides consumption while the market shock passes. Combining the findings presented above paints a stark picture for the left out group in particular. As they attempt to manage sales rates and price per animal to ensure household consumption in the face of more relative variability in milk production than the other groups, they have to sell the same amount in recovery as in drought to ensure sufficient consumption. When we return to the long-term herd size change implications of Figure 3, this threatens them with a potential long-term slide towards eventual stocklessness in the context of repeated shocks.

\section{Conflict shocks}

We first consider exposure to conflict risk. The PARIMA study asked whether there was any pronounced insecurity in a given month in each of our 11 sites in the monthly community survey; $23 \%$ of the time, the answer was yes. However, in contrast, we asked how many times there was a raid that injured people and/or stole animals. Such events were reported for only $6 \%$ of observations. The

Table 10 Price per TLU in drought and recovery

\begin{tabular}{lll}
\hline & $\begin{array}{l}\text { Price per TLU } \\
\text { in drought }\end{array}$ & $\begin{array}{l}\text { Price per TLU } \\
\text { in recovery }\end{array}$ \\
\hline 1) Left out & $\$ 86.23$ & $\$ 78.02$ \\
2) Moving from & $\$ 94.89$ & $\$ 125.78$ \\
3) Staying with & $\$ 85.64$ & $\$ 98.20$ \\
4) Combining & $\$ 81.19$ & $\$ 118.33$ \\
Significant difference in & $t 12, t 13, t 14$, & $t 12^{* * *}, t 13^{* *}, t 14^{* * *}$, \\
means by groups, $t$-statistics & $t 23, t 24, t 34$ & $t 23^{*}, t 24, t 34^{*}$ \\
\hline
\end{tabular}

***Significant difference at $1 \%,{ }^{*}$ significant difference at $5 \%,{ }^{*}$ significant difference at $10 \%$ perception of insecurity is greater than the actual risk. McPeak et al. write:

The contrast between insecurity and the actual occurrence of raids and violence is striking, especially given the study region's reputation as one of the most conflictive and insecure in Kenya and Ethiopia (see Kenya Human Rights Commission 2000; Galaty 2002, 2005; Mwangi 2006; Straight 2009). It indicates that the impact of insecurity is much more widely felt than the direct impact of raids and violence. Insecurity was described by respondents as being the result of conflicts between neighboring groups about using particular areas of the rangeland or water points; fear that conflict taking place elsewhere between one's own group and another group would spill over and lead to an outbreak of conflict in the home area; and general issues related to robbery or attacks on vehicles passing through the area. In many cases, the insecurity influenced grazing patterns, so that productive grazing areas were unused and became 'no-man's lands'.... impacts of insecurity are experienced in many ways beyond the actual loss of livestock or human life to raiders.

(McPeak et al. 2012: 69)

Sensitivity to conflict risk As just discussed, the primary way in which people experience conflict risk is forgoing grazing in pasture lands that are insecure. As reported in Haro et al. (2005), residents of northern Kenya expressed frustration that around half their traditional grazing area had been rendered unusable due to fears of conflict as it relates to the mobility decisions in Table 8. However, another aspect of conflict is that 
animals can be stolen or lost. We combined these categories in the survey as it was not always clear to herders whether an animal was stolen or lost. In general, this was a relatively small problem, usually accounting for no more than a percent of herd size change overall in a given round for all of the different groups. Herders informal estimates were that about three fourths of missing animals were probably lost and the remainder stolen. Most notably in the PARIMA study, the difference in this kind of loss may be more geographic than based on livelihood group. Animals reported as being lost and stolen in the data set are predominantly from one site, Dirib Gumbo in Kenya. This large Boran community lives on Marsabit Mountain, and members have limited access to lowland grazing areas off the mountain. When they were forced by drought in 2000 to conduct long distance migration across unfamiliar lowland grazing zones occupied by other ethnic groups, a significant share of animals was either lost or stolen along the way.

One final piece of evidence to consider concerning sensitivity to raid loss is that we asked households in the baseline to report the magnitude of raid losses in the decade of the 1990s; 27\% of 336 households reported some raid-related loss in the ten-year period. Rarely was more than one event experienced per household. The mean loss was 18.6 TLU, while the median was 5.0 TLU. Though not insignificant, these are relatively small when placed against the magnitude of drought losses experienced as reflected in Figure 3.

The capacity to cope with conflict risk is for the most part an issue beyond the control of the household. Coping with conflict risk is located in three more collective domains. First, groups of herders carry weapons to grazing areas and serve as mutual defence forces. Second, community groups can create mechanisms to attempt to resolve conflict across ethnic frontiers (Haro et al. 2005). Finally, the forces of state control such as police and military can be called in to protect citizens; as demonstrated by McPeak (2003), during periods of conflict, herding households tend to retreat towards towns where there are police posts.

\section{Land rights shocks}

Over the past decades, there has been a documented growth in de facto privatization of communally held lands, where the commercial value or scale of livestock export has markedly increased (Flintan et al. 2011; Yohannes 2012). The proliferation of fenced enclosures around dryland towns has grown in southern Ethiopia and northern Kenya and was a widespread practice in Somalia's drylands as early as the 1970s (Behnke 1988; Little 1992). The leasing of private enclosures by traders have been spreading in northern Somalia and parts of lowland Ethiopia as temporary feed lots for trade animals destined for export.

Some notable shocks that have arisen as a result of land privatization are conflicts due to multiple claims on a given piece of land, loss of livestock passage corridors and public spaces, live fencing material growing to take over land used for other purposes and if eaten had a harmful effect on livestock, land grabbing and dispossession of customary pastoral land users, and environmental degradation on surrounding rangelands (Odouri et al. 2006). In southern Ethiopia, the renting of grazing lands by traders for market animals after purchases can be directly traced to the past five years and the increase in high-value export trade in the region (Tiki and Little 2013). As involvement in export markets grows and the demand increases for high-quality animals, one can expect that private grazing leases or outright purchases of communal lands may grow. Unfortunately, these changes occur in settings where communal access to land provide flexible responses to temporal and spatial variability in pasture availability, which are important means of coping with the kinds of climate shocks that were previously discussed.

\section{Resilience measures}

We now turn to the question of how to construct a measure that captures the concept of resilience in pastoralism. For a broader review of the literature on resilience in drylands, refer to Walker and Abel 2002, Walker and Salt 2006, Bahadur et al. 2010, DfID 2011, Headey 2012, USAID 2012, Vatla et al. 2012, Bene et al 2012, World Bank 2013, Maxwell et al. 2013, Frankenberger and Nelson 2013, and Hesse et al. 2013. We begin by contrasting four different measures of resilience based on the findings in the 'Analysis' section. Given the importance of income and income variability over time discussed above, one measure of resilience to consider represents how long it took for a household to recover to the income level observed in the first survey of June 2000, a 'bounce back' measure of well-being, called income recover resilience index. ${ }^{5}$ A second income-based measure considered records how long it took households to attain an income equal to an extreme poverty line threshold of $\$ 0.50$ per person per day, called income threshold resilience index. ${ }^{6}$ A different approach is taken given the critical role played by assets in this context, in particular livestock assets. A third measure considered is an asset index that records how long it took the household to bounce back to the herd size they had in March 2000, called asset recover resilience index. The fourth is also an asset measure, but it records how long it took the household to get to a herd size threshold of 4.5 TLU per capita, called asset threshold resilience index. ${ }^{7}$ Note that our measures are all 
defined over the time span for which data were gathered from March 2000 to June 2002. ${ }^{8}$

The first clear finding from Table 11 is that the 'income recover resilience index' gives results that are misleading given what we know about relative well-being and vulnerability from Table 1 and from the analysis presented in the 'Analysis' 4. Given the view that 'The converse of resilience is vulnerability' (Hesse et al. 2013, p. 4), we would expect there to be some inverse pattern between the coefficient of variation over time for household total income over time and the measure of resilience. This is not the case by this first measure. The poorest and most vulnerable households 'bounced back' the quickest and the wealthiest and least vulnerable took the longest to bounce back. This largely reflects the phenomena elaborated on by Barrett and Constas (2014). There are potentially 'good' and 'bad' steady state outcomes. A higher income steady state is a good outcome while a lower income poverty trap is a bad outcome. Using the income recover measure, the poor households were able to recover to where they were when we first encountered them, but that was to a pretty low level of well-being - the 'bad' outcome of chronic poverty. The better off groups took longer but were headed to a better outcome as captured by the mean income finding. In contrast, the 'income threshold resilience index' gives results that seem more consistent with the well-being indicators of mean income and lower vulnerability. The left out are the worst off by this measure, the combining the best off, and the other two groups lie in between which is much more consistent with the results presented in the 'Analysis' section.

Turning to the 'asset recover resilience index', we again find that returning to the opening period level is not particularly helpful in measuring resilience. This measure gives us no statistically significant differences among the groups and does not tell us anything informative about the households in the different groups bouncing back in this domain. On the other hand, the 'asset threshold resilience index' that records bouncing back to the 4.5 TLU threshold is strongly related to being in one of the above median herd size in March 2000 groups, with the combining group even more resilient by this measure than the staying with group. The other two groups show very low resilience according to this measure.

In contrast to the income threshold resilience measure, the moving from group performs relatively poorly, as might be expected given that they are moving from the asset used to define the resilience index. While further analysis could provide more rigorous analysis of these patterns, it would appear that measures that define resilience as bouncing back to a threshold common to all households, and meeting some definition of a 'good' equilibrium, are better able to capture the meaning of the concept discussed in the literature than are measures that define bouncing back to where one started. This last measure is in many ways a restatement of a line of thought in the pastoral literature that can be traced to Dahl and Hjort's Having Herds (1976); the more animals one has going into a drought, the more one can hope to have coming out of the drought.

However, as we have seen, the livelihood groups are not necessarily sharing the same objectives. Particularly for the staying with group, a measure that prioritizes income recovery over asset recovery is less reflective of their livelihood objective. Conversely, the moving from group is less oriented towards asset resilience and more towards income resilience. As a final set of contrasts to measuring resilience, we combine these measures in two different ways in the final two columns of Table 11. The first looks at the average of the income and asset threshold resilience index for each household, and the second looks at the maximum of these indices for each household. This allows some allowance for the fact that the different livelihood groups may place different emphasis on income resilience compared to asset resilience.

These results are broadly consistent in the ordinal ranking of the different livelihood groups and seem consistent with the findings in the 'Analysis' section. In both of these measures, the least resilient are the left out group and the most resilient are the combining group.

Table 11 Average resilience indices, by sub-group (1 is most resilient, 0 is least resilient)

\begin{tabular}{|c|c|c|c|c|c|c|}
\hline & $\begin{array}{l}\text { Income recover } \\
\text { resilience index }\end{array}$ & $\begin{array}{l}\text { Income threshold } \\
\text { resilience index }\end{array}$ & $\begin{array}{l}\text { Asset recover } \\
\text { resilience index }\end{array}$ & $\begin{array}{l}\text { Asset threshold } \\
\text { resilience index }\end{array}$ & $\begin{array}{l}\text { Average threshold } \\
\text { resilience index }\end{array}$ & $\begin{array}{l}\text { Maximum threshold } \\
\text { resilience index }\end{array}$ \\
\hline 1) Left out & 0.827 & 0.156 & 0.464 & 0.035 & 0.095 & 0.172 \\
\hline 2) Moving from & 0.621 & 0.305 & 0.486 & 0.004 & 0.269 & 0.426 \\
\hline 3) Staying with & 0.608 & 0.237 & 0.444 & 0.302 & 0.154 & 0.307 \\
\hline 4) Combining & 0.533 & 0.531 & 0.425 & 0.446 & 0.488 & 0.658 \\
\hline $\begin{array}{l}\text { Significant difference } \\
\text { in means by groups, } \\
t \text {-statistics }\end{array}$ & $\begin{array}{l}t 12^{* * *}, t 13^{* * *}, \\
t 14^{* * *}, \\
t 23, t 24, t 34\end{array}$ & $\begin{array}{l}t 12, t 13^{* *}, t 14^{* * *} \\
t 23, t 24^{* * * *}, t 34^{* * *}\end{array}$ & $\begin{array}{l}t 12, t 13, t 14 \\
t 23, t 24, t 34\end{array}$ & $\begin{array}{l}t 12^{* * *}, t 13^{*}, t 14^{* * *}, \\
t 23^{* * *}, t 24^{* *}, t 34^{* * *}\end{array}$ & $\begin{array}{l}t 12^{* * *}, t 13^{*}, t 14^{* * *}, \\
t 23^{* * *}, t 24^{* *}, t 34^{* * *}\end{array}$ & $\begin{array}{l}t 12^{* * *}, t 13^{*}, t 14^{* * *}, \\
t 23^{* * *}, t 24^{* *}, t 34^{* * *}\end{array}$ \\
\hline
\end{tabular}

***Significant difference at $1 \%,{ }^{*}$ significant difference at $5 \%,{ }^{*}$ significant difference at $10 \%$ 
While this is generally consistent with what we knew about well-being and vulnerability from Table 1, note that in Table 1 and in much of the analysis, we were not always able to order the combining group (2) and the staying with group (3). These final two resilience measures indicate that the combining group is more resilient than the staying with group. This is at least indicative that efforts to facilitate moves from staying with to combining or moving from could be resilience enhancing. In contrast, moves from staying with to left out would decrease resilience. What broader efforts could enhance resilience in pastoral areas? We discuss a few important opportunities in the 'Resilience-enhancing impacts' section before concluding in the 'Conclusions' section.

\section{Resilience-enhancing impacts}

\section{Transport infrastructure and market towns}

Of regional importance, the transportation network for roads in East African dryland areas has been expanding and is planned to expand further. While more targeted at increasing regional trade and easing export of natural resources to get to more lucrative markets, these developments have implications for dryland residents. Some trips to distant markets are no longer as distant and subject to less unpredictability. However, while this is a benefit for those dryland residents with connections outside of the area, it also makes dryland areas more accessible to those who are currently not residents. The 'land grabbing' in dryland areas of Ethiopia, Kenya, and Tanzania will likely become more pronounced as formerly inaccessible drylands become increasingly accessible and hence valuable to investors (Little et al. 2010; Flintan et al. 2011; Galaty 2012). While these improvements in transport create new opportunities for more price responsive marketing and value added processing, it is by no means clear that the benefits to the majority of dryland residents will outweigh the costs if current trends continue.

Relatedly, as these transport networks improve, the towns along the roads of this area will change with new opportunities arising and old ones requiring adaptation. A town such as Merille in Kenya had much market activity centred on being a mid-day stopping point for Isiolo-Marsabit voyages. Now, it reached in a matter of two hours, making it no longer a mid-day stopping point. Tea shops, trade, commerce, and overall market integration create new opportunities for those who adapt to the changing market conditions. As outlined in Desta et al. (2006), collective action can interact with external support to fill new market niches with those exiting pastoralism, in particular females who have little to no access to livestock. The category described as left out above may be possible to include as town-based economic activity increases. Spontaneous sedentarization is a process that needs support and management; currently, it is taking place largely in an unplanned and unmanaged manner that can lead to negative consequences in the future. The latter includes encroachment of settlements on critical water and grazing resources, excessive degradation of forests around towns, and spontaneous land enclosures and privatization. These processes affect both rich and poor herders, as well as ex-pastoralists (especially women) who depend on surrounding lands and water for small-scale farming and other activities (Fratkin and Roth 2004).

\section{Cross-border trade}

Often, the presence of international borders provides both economic opportunities as well as challenges for dryland communities that reside near them. On the positive side, residents may find better market options for their livestock and services across nearby borders than within their own countries and may assist with responding to those market-induced shocks previously discussed. They also often have considerably better availability of and lower prices for many consumer goods in border zones than elsewhere in the drylands. In the Horn of Africa, the volume of informal cross-border trade in animals annually accounts for considerably more trade than export trade (Little 2006; Little et al. 2010). Even the export of live animals from Somalia/ Somaliland, the largest live animal export market in the region and among the biggest in the world, is fueled by informal cross-border trade between eastern Ethiopia and Somaliland (Desta et al. 2011). Depending on the year, approximately $50 \%$ of the small stock that are exported from Berbera, Somaliland, and Bossaso, Puntland (Somalia), are sourced across the border in eastern Ethiopia (Majid 2010: 5). Along Somalia's and Ethiopia's other borders, as well as Kenya's borders, informal cross-border trade in livestock also is considerable (Aklilu et al. 2013).

On the negative side, borderland dryland communities confront certain economic and political risks that other locations do not. Animals can be confiscated by border officials at considerable economic loss to traders and herders, while shipments of food and other goods can also be confiscated, which can drive up local consumer prices and aggravate food security problems in border communities. Studies show the widespread hardships for consumers and businessmen when governments halt informal cross-border trade (Little 2013b).

\section{Livestock insurance}

Over the past seven years, the USAID BASIS project in collaboration with the International Livestock Research Institute, universities, and other donors has been developing a pilot project concerning IndexBased Livestock Insurance as a market-based approach 
to risk management in northern Kenya. This was also launched recently in southern Ethiopia. The basic concept is that if there are historical records of covariate livestock mortality, such as exist in northern Kenya because of the World Bank-funded Arid Lands Resource Management Project (ALRMP), these records can be regressed on historical remote-sensed satellite imagery of rangeland condition. In the northern Kenya case, remotesensed NDVI data was available for each 10-day period for 8 by $8 \mathrm{~km}$ blocks from 1981 to present. The historical, community-level mortality data from ALRMP monitoring efforts was regressed on NDVI data to develop an index (see Chantarat et al. 2013 for details). They can then be used to input real-time vegetation conditions as captured in NDVI in order to predict community-level covariate mortality under these conditions. Contracts can then be written between insurance companies and livestock keepers (and backed by reinsurance companies) to provide compensation payments to herders in the event that the mortality index indicates that a given level of covariate mortality has been reached for a given season.

Notably, compensation is only triggered once a specified threshold mortality (15\% in current contracts) has been surpassed, and only compensates for losses in excess of the threshold. Further, contracts are sold on a TLU basis so compensation is proportionate to the number of contracts purchased, not the actual herd size or even the magnitude of losses realized by a herder buying insurance (see Mude et al. 2011 for details).

Common problems are a lack of understanding by herders that the contracts are tied to a specific time frame, payments reflect predicted covariate loss not actual loss, there is a level of loss that is uncompensated up to the trigger, and one has to buy the insurance to be eligible for compensation. It will take time and effort to move livestock production in East African drylands towards a market-based insurance system, but these early efforts demonstrate the idea is at least feasible. Currently, efforts are centred on ensuring extension systems which are up to the challenge of creating informed demand.

Remaining ahead is the challenge of identifying a sustainable business model to provide insurance as a commercial product. It is currently subsidized by donors and is being developed as a pilot project. Transitioning from this phase of the product development to a sustainable, commercially available product that will enhance capacity to cope with climate change is a challenge that lies ahead.

Finally, it is likely that this product will benefit those who are from the wealthier end of the spectrum and, given the inequality of livestock ownership revealed in Figure 1, will not have a significant direct impact on a large share of the population. Other policies will be necessary for poverty reduction in these areas. We note in closing that ongoing work in northern Kenya is contrasting poverty reduction through income protection (cash transfers) as part of the Hunger Safety Net programme, with poverty reduction through asset protection (index insurance) as part of the Index-Based Livestock Insurance programme. We may learn about complementarities between these kinds of interventions as we gather more evidence through the monitoring and evaluation effort.

\section{Conclusions}

In this study, we have adapted the World Bank's framework on resilience in drylands to investigate panel data gathered from 330 households in 11 communities in Kenya and Ethiopia in 2000 to 2002. We find that the livelihood groups we constructed as part of our analysis do experience shocks differently and in multifaceted ways.

Climate shocks are the key variable driving dryland production systems. We have considered three kinds of responses households deploy to deal with climate shocks. First, households are differentially using markets to change offtake decisions and restocking decisions in response to climate shocks. Second, mobility is a strategy adopted by households in response to climate shocks, particularly those with larger herds. Third, humanitarian assistance in the form of food aid helps at the margin but is not near the scale needed to compensate for the impact of the climate shock on food security.

Health shocks are more pronounced the more spatially concentrated people and animals are, especially for poorer households. For example, outbreaks of foot-andmouth disease (FMD) in East Africa generally occur during droughts when animals are concentrated around water points. We find evidence that the different livelihood groups differ in their exposure and ability to prevent health shocks. In particular, health shocks are less likely to impact households with access to cash to make preventative or compensating expenditures. The availability of human and animal health inputs is conditional on access to cash; ensuring input availability is a necessary not a sufficient condition for better health outcomes.

Market shocks can occur due to drought, market quarantines on animal sales, global price changes, or other factors. During a market shock, livestock prices often plummet while food prices increase. This is a common shock-induced pattern in drylands. Policies to improve fodder and feed markets could help herders better time their livestock sales during climate-induced market shocks, while better veterinary services and diagnoses could reduce livestock trade/export bans. Our evidence indicates that the common price shock of the drought phase is followed by a recovery period where different 
sub-groups experience different prices in markets, an issue which merits further analysis and explanation.

Given the identified importance of livestock mobility and an awareness of the increased competition for land, policy-makers should consider the impact of promoting alternative uses of land on extensive livestock production systems and carefully weigh the costs and benefits. Conversion of communal land into private feedlots or irrigated cultivation reduces the land available for communal grazing and can cut off access to critical resources. Niches that allow value addition to livestock production should be identified to find ways for changing land use to complement rather than substitute for livestock production.

One finding of particular interest for refining ideas of resilience is that the measures we constructed for resilience that were based on bouncing back to the starting point were not informative compared to those that were based on bouncing back to a common threshold.

The heterogeneity of experiences we have outlined in this study indicates that the idea of 'pastoral resilience' may mask important differentiation for sub-groups within the population of pastoral areas. Not all groups experience shocks in the same manner, and this needs to be taken into account for policy and programmes in pastoral areas. For those poorer groups who are most vulnerable to shocks, we note that asset protection programmes, such as the Index-Based Livestock Insurance effort, and cash transfer programmes, such as the Productive Safety Net, hold promise for resilience in dryland areas, but their impacts merit further study.

\section{Endnotes}

${ }^{1}$ While stratification by the median value on two key variables is admittedly a coarse filter, we were attempting to build on use of a similar framework by UNOCHA-PCI 2007 elaborated on by Catley et al. 2012 (and recently modified by Lind et al. 2015). Also, note that a similar 2 by 2 framework was proposed in the Theory of Change and Development Hypothesis for the USAID grant SOL623-12-000008: Resilience and Economic Growth in the Arid Lands-Improving Resilience Project in Kenya that was used to guide development activities in parts of our study areas beginning in 2012 .

${ }^{2}$ Community-level prices were gathered monthly at the market level in each community, and results were converted to averages over three-month periods corresponding to the survey rounds.

${ }^{3}$ Average seasonal rates are reported; these are changes over three-month periods.

${ }^{4}$ The quantity of food aid received is converted to a cash value using local market prices for that community and period for the commodities distributed as food aid.
${ }^{5}$ These measures are normalized on a zero-one scale. The resilience indices are structured so that 1 means households bounced back by the next round; a number between zero and one means they recovered a given number of survey rounds later as a fraction of total survey rounds so that lower numbers meaning later in the survey period, a zero means they never bounced back during ensuing survey rounds.

${ }^{6}$ An income-based extreme poverty line used in previous work with this data (Barrett et al. 2008); 81\% of observations are below this threshold.

${ }^{7}$ The threshold is based on previous work in pastoral systems in the area that indicates this is a threshold for mobility in pastoral systems (Fratkin and Roth 1990); $82 \%$ of observations are below this threshold.

${ }^{8}$ While this captures a drought and onset of recovery in a full 'boom and bust' cycle, in pastoralism, the full 'boom' phase generally lasts longer than the part of the recovery period analysed in this study.

\section{Authors' contributions}

Both authors read and approved the final manuscript.

\section{Competing interests}

The authors declare that they have no competing interests.

\section{Declarations}

This is our original work, has not been published elsewhere, and is not under review elsewhere currently.

\section{Author details}

'Syracuse University, Syracuse, NY, USA. ²Emory University, Atlanta, GA, USA.

Received: 8 October 2016 Accepted: 17 February 2017

Published online: 15 June 2017

\section{References}

Aklilu, Y., Little, P.D., Mahmoud, H., and McPeak, J. 2013. Market access and trade issues affecting the drylands in the Horn of Africa. Brief prepared by a Technical Consortium hosted by CGIAR in partnership with the FAO Investment Centre. Technical Consortium Brief 2. Nairobi: International Livestock Research Institute.

Amanor, K.S. 1995. Dynamics of herd structures and herding strategies in West Africa: A study of market integration and ecological adaptation. Africa 65: 351-394.

Bahadur, A.V., M. Ibrahim, and T. Tanner. 2010. Strengthening climate resilience. Brighton: Institute of Development Studies. Strengthening climate resilience discussion paper 1 .

Barrett, C.B., and M. Constas. 2014. Towards a theory of resilience for international development applications. Proceedings of the National Academy of Sciences 40(111): 14625-14630.

Barrett, C.B., and W. Luseno. 2004. Decomposing producer price risk: A policy analysis tool with an application to northern Kenyan livestock markets. Food Policy 29: 393-405.

Barrett, C.B., F. Chabari, D. Bailey, P.D. Little, and D.L. Coppock. 2003. Livestock pricing in the northern Kenya rangelands. Journal of African Economies 12(2): 127-155.

Behnke, R. 1988. ODI pastoral development network paper 25b. Range enclosure in Central Somalia: Overseas Development Institute. London.

Bene, C., R. Wood, A. Newsham, and M. Davies. 2012. Resilience: New Utopia or new tyranny? Reflection about the potentials and limits of the concept of resilience in relation to vulnerability reduction programmes. IDS Working Paper, Vol. 2012, Number 405. Brighton, UK: Institute of Development Studies. 
Catley, A., J. Lind, and I. Scoones. 2012. Development at the margins: Pathways of change in the Horn of Africa. London: Routledge.

Chantarat, S., A. Mude, C.B. Barrett, and M. Carter. 2013. Designing index-based livestock insurance for managing asset risk in northern Kenya. Journal of Risk and Insurance 80(1): 205-237.

Dahl, G., and A. Hjort. 1976. Having herds: Pastoral herd growth and pastoral economy. Stockholm: Stockholm Studies in Social Anthropology.

De'Besi, $G_{\text {., }}$ and O. Thieme. 2013. Optimum use of milk in traditionally managed cattle herds in the tropics. Tropical Animal Health and Production 45: 1079-1086.

Debsu, D.N. 2013. Climate risks and market opportunities: Livestock trading and marketing in Borana, southern Ethiopia. Atlanta: Climate-induced vulnerability and pastoralist livestock marketing chains in southern Ethiopia and northeastern Kenya" Project, Development Studies Program, Emory University.

Desta, S., G. Gebru, S. Tezera, and D.L. Coppock. 2006. Linking pastoralists and exporters in a livestock marketing chain: Recent experiences from Ethiopia. In Pastoral livestock marketing in Eastern Africa: Research and policy challenges, 2006th ed, ed. J. McPeak and P. Little. Warwickshire: Intermediate Technology Publications.

Desta, S., W. Berhanu, A. Sebsibe, and E. Guerne-Bleich. 2011. Assessment of cross border informal livestock trade in Somali region. Addis Ababa: Food and Agriculture Organization.

DfID. 2011. Defining disaster resilience: A DFID approach paper. London: DFID. 19 pages.

Flintan, F., B. Tache, and A. Eid. 2011. Rangeland fragmentation in traditional grazing areas and its impact on drought resilience of pastoral communities: Lessons from Borana, Oromia and Harshin, Somali Regional States, Ethiopia. Addis Ababa: Regional Learning and Advocacy Programme and Save the Children UK.

Frankenberger, T., and S. Nelson. 2013. Summary of the expert consultation on resilience measurement for food security. Tucson: TANGO International.

Fratkin, E., and E. Roth. 1990. Drought and economic differentiation among Ariaal pastoralists of Kenya. Human Ecology 18(4): 385-402.

Fratkin, E., and E. Roth (eds.). 2004. As nomads settle: Social, health, and ecological consequences of pastoral sedentarization in northern Kenya. New York: Kluwer Academic/Plenum Publishers.

Fratkin, E., E. Roth, and M.A. Nathan. 2004. Pastoral sedentarization and its effects on children's diet, health, and growth among Rendille of northern Kenya. Human Ecology 32(5): 531-559.

Galaty, J. 2002. Vue sur la violence: les frontieres du conflit pastoral au Kenya. Anthropologie et Societes 26(1): 107-26.

Galaty, J. 2005. Time, Terror, and Pastoral Inertia: Sedentarization and Conflict in Northern Kenya. In As Pastoralists Settle: Social, Economic, and Health Consequences of Pastoral Sedentarization in Northern Kenya, ed. E. Roth and E. Fratkin, 53-68. New York: Kluwer Academic Publishers.

Galaty, J. 2013. Land Grabbing in the Eastern African Rangelands. In Pastoralism and Development in Africa: Dynamic Change at the Margins, ed. A. Catley, J. Lind, and I. Scoones, 143-153. New York: Earthscan.

Haro, G., G. Doyo, and J. McPeak. 2005. Linkages between community, environmental, and conflict management: Experiences from northern Kenya. World Development 33(2): 285-299.

Headey, D. 2012. Enhancing resilience in the Horn of Africa: An exploration into alternative investments. Washington, DC: International Food Policy Research Institute (IFPRI). IFPRI discussion paper 01176.

Herren, U.J. 1992. Cash from camel milk. Nomadic Peoples 30: 97-113.

Hesse, C., S. Anderson, L. Cotula, J. Skinner, and C. Toulmin. 2013. Building climate resilience in the Sahel. Paper presented to the DFID Consultation workshop on Building Resilience in the Sahel and Planned Building Resilience and Adaptation to Climate Extremes and Disasters (BRACED) Programme - 17th July.

Holden, S., D.L. Coppock, and M. Assefa. 1991. Pastoral dairy marketing and household wealth interactions and their implications for calves and humans in Ethiopia. Human Ecology 19(1): 35-59.

Kenya Human Rights Commission. 2000. The Forgotten People Revisited: Human Rights Abuses in Marsabit and Moyale Districts. Nairobi: Kenya Human Rights Comission.

Lind, J. R. Sabates-Wheeler, and S. Kohnstamm. 2015. Changes in the arid and semi-arid lands in East Africa: Evidence synthesis and data mapping on poverty, vulnerability, livelihoods and resilience. Institute of Development Studies, University of Sussex. Mid-Stage Progress Report.

Little, P.D. 1992. The Elusive Granary. Cambridge: Cambridge University Press.

Little, P.D. 2006. Working across borders: Methodological and policy challenges of cross-border livestock trade in the Horn of Africa. In Pastoral livestock marketing in eastern Africa: Research and policy challenges, ed. J. McPeak and P.D. Little, 169-185. Warwickshire: ITDG Publications.

Little, PD. 2013a. How pastoralists perceive and respond to market opportunities: The case of the Horn of Africa. Paper presented at the Conference on "Mainstreaming Livestock Value Chains: Bridging the Research Gap between Household Analysis and Policy Modeling". Sponsored by ILRI and the CGIAR, Accra, Ghana, November 5-6.

Little, PD, 2013b. Unofficial trade when states are weak: The case of cross-border livestock trade in the Horn of Africa. In M. Bollig, J. Pauli, and Hans-Peter Wotzka, eds. African Pastoralism: Past, Present and Future-The Emergence, History and Contemporary Political Ecology of African Pastoralism. Pp. 387410. New York, NY and Oxford, UK: Berghahn Books

Little, P.D., K. Smith, B.A. Cellarius, D.L. Coppock, and C.B. Barrett. 2001. Avoiding disaster: Diversification and risk management among East African herders. Development and Change 32(3): 401-433.

Little, P.D., J. McPeak, C. Barrett, and P. Kristjanson. 2008. Challenging orthodoxies: Understanding pastoral poverty in East Africa. Development and Change 39(4): 585-609

Little PD, Behnke R, McPeak J and G Gebru. 2010. Future scenarios for pastoral development in Ethiopia, 2010-2025. Report no 2. Pastoral Economic Growth and Development Policy Assessment, Ethiopia, Addis Ababa, and Department for International Development (DfID), Ethiopia. 57 p.

Majid, N. 2010. Livestock trade in the Djibouti, Somali and Ethiopian borderlands. Paper AFP BP 2010/01. London: Chatham House

Maxwell, D., B. Vaitla, G. Tesfay, and N. Abadi. 2013. Resilience, food security dynamics, and poverty traps in northeastern, Ethiopia: Analysis of a bi-annual panel set, 2011-2013. Medford: Feinstein International Center, Tufts University.

McPeak, J.G. (2003). Analyzing and Addressing Localized Degradation in the Commons. Land Economics 79(4):515-536.

McPeak, John G. and Cheryl R. Doss. 2006. Confronting the risk of asset loss: What role do livestock transfers in northern Kenya play? Journal of Development Economics 81(2): 415-437.

McPeak, J., P.D. Little, and C. Doss. 2012. Risk and Change in an African Rural Economy. London: Routledge.

Mude, A., S. Chantarat, C. Barrett, M. Carter, M. Ikegami, and J. McPeak. 2011. Insuring against drought-related mortality: Piloting index-based livestock insurance in northern Kenya. In Towards Priority Actions for Market Development for African Farmers, Proceedings of an International Conference 13-15 May 2009, Nairobi, Kenya. AGRA and ILRI, Nairobi, Kenya.

Mwangi, O.G. 2006. Kenya: Conflict in the 'Badlands': The Turbi Massacre in Marsabit District. Review of African Political Economy 33(107): 81-91.

Nduma, I., P. Kristjanson, and J. McPeak. 2001. Diversity in income generating activities for sedentarized pastoral women in northern Kenya. Human Organization 60(4): 319-325.

Odouri, S.M., M.S. Alim, and N. Gomes. 2006. Environmental degradation in the Sool Plateau and Gebi Valley: Sanaag region of northern Somalia. Final Report. Nairobi: Horn Relief

Schlee, G. 1989. Identities on the move: Clanship and pastoralism in northern Kenya. Nairobi: Gideon Were Press.

Schlee, Y., and E. Watson. 2009. Changing identifications and alliances in northeast Africa. New York: Berghahn.

Schwartz, H., S. Shaabani, and D. Walther (eds.). 1991. Range management handbook of Kenya. Nairobi: Ministry of Livestock Development.

Sikana, P., and C. Kerven. 1991. The impact of commercialisation on the role of labour in African pastoral societies, pastoral development network set 31. London: ODI.

Sikana, P., C. Kerven, and R. Behnke Jr. 1993. From Subsistence to Specialized Commodity Production: Commercialisation and Pastoral Dairying in Africa. London: Pastoral Development Network, ODI.

Spear, T., and R. Waller (eds.). 1993. Being Maasai: Ethnicity and identity in East Africa. Athens: Ohio Univerisity Press.

Straight, B. 2009. Making sense of violence in the "Badlands" of Kenya. Anthropology and Humanism 34(1): 21-30.

Swift, J. 1979. West African Pastoralist Systems. Ann Arbor: University of Michigan.

Tiki, W. and P.D. Little. 2013. Influences of climate, coping strategies and middle eastern markets on the livestock trade in southern Ethiopia: Preliminary observations. Research Brief RB-13-2013. Ft. Collins, CO: Feed the Future Innovation Lab for Collaborative Research on Adapting Livestock Systems to Climate Change, Colorado State University.

Turner, M., and T. Williams. 2002. Livestock market dynamics and local vulnerabilities in the Sahel. World Development 30(4): 683-705. 
USAID. 2012. Building resilience to recurrent crisis: USAID policy and program quidance. Washington: USAID.

Vatla, B. G. Tesfay, M. Rounseville, and D. Maxwell. 2012. Resilience and livelihoods change in Tigray Ethiopia, Feinstein International Center. Tufts University.

Walker, B., and N. Abel. 2002. Resilient rangelands: Adaptation in complex systems. In Panarchy: Understanding transformations in systems of humans and nature, ed. L.H. Gunderson and C.S. Holling, 293-314. Washington, D.C: Island Press.

Walker, B., and D. Salt. 2006. Resilience thinking: Sustaining ecosystems and people in a changing world. Washington, DC: Island Press.

Wane, A., V. Ancey, and I. Toure. 2010. Pastoralisme et Recours aux Marches: Cas du Sahel Senegalais (Ferlo). Cahiers Agricultures 19(1): 14-20.

World Bank. 2013. The economics of resilience in the drylands of sub-Saharan Africa, concept note for a regional flagship report. Washington, DC: World Bank.

Yohannes GebreMichael 2012. Resilience of households' livelihoods to hazards in Somaliland. Save the children Somalia

\section{Submit your manuscript to a SpringerOpen ${ }^{\circ}$ journal and benefit from:}

- Convenient online submission

- Rigorous peer review

- Immediate publication on acceptance

- Open access: articles freely available online

- High visibility within the field

- Retaining the copyright to your article

Submit your next manuscript at $>$ springeropen.com 